\title{
Embryonic and Early Fetal Development of the Human Neocortex
}

\author{
Gundela Meyer, ${ }^{1}$ Jean Pierre Schaaps, ${ }^{2}$ Louis Moreau,,2 and André M. Goffinet ${ }^{3}$ \\ ${ }^{1}$ Department of Anatomy, Faculty of Medicine, University La Laguna, 38071 La Laguna/Tenerife, Spain, ${ }^{2}$ Department of \\ Embryology, University of Liege Medical School, B4000 Liege, Belgium, and ${ }^{3}$ Neurobiology Unit, University Namur \\ Medical School, B5000 Namur, Belgium
}

Early corticogenesis was studied in human embryos and early fetuses from Carnegie stages 16 to 22 (5-8 gestational weeks) by using immunohistochemistry for Reelin (Reln), calretinin (CR), and glutamic acid decarboxylase (GAD). A first population of Reln-positive cells appears in the neocortical anlage at stage 16 and increases in number at stages 17-18. At stages 19-20, a monolayer of horizontal CR- and GAD-positive, Reln-negative neurons forms in the preplate, whereas Reln-positive cells shift into a subpial position. Another cell class, the pioneer projection neuron, is CR-positive but GAD- and Reln-negative; pioneer cells contribute early corticofugal axons. Pioneer cells first appear below the monolayer at stage 20 and form a pioneer plate at stage 21 . The cortical plate (CP) proper emerges at

The correct establishment of the six-layered neocortex is critically dependent on a tightly regulated developmental program that begins to unfold before the appearance of the cortical plate (CP). Disturbances of this complex process are increasingly recognized as major causes of intractable epilepsies and mental disabilities in childhood (Faiella et al., 1997; des Portes et al., 1998; Gleeson et al., 1998, 1999; Francis et al., 1999).

Numerous experimental studies provided insight into the cellular dynamics and genetic regulation of early corticogenesis. Neurons are generated in ventricular zones (VZs) of cortical wall and ganglionic eminence and reach their destination by both radial and tangential migration (Rakic, 1972; Anderson et al., 1997; Lavdas et al., 1999). The first postmitotic cells settle in the external field of the cortical anlage and form the so-called preplate (Rickmann and Wolff, 1981). When the CP appears, this early population becomes divided into two components, namely Cajal-Retzius cells in the marginal zone (MZ) and subplate cells below the CP (Marín-Padilla, 1971, 1972). Formation of the CP then proceeds by progressive adjunction of new immigrant neurons after an "inside-out" gradient (Angevine and Sidman, 1961; Rakic, 1974). The extracellular protein Reelin (Reln), secreted by Cajal-Retzius cells, is critically involved in this process (D’Arcangelo et al., 1995, 1997; Lambert de Rouvroit and Goffinet, 1998); in the reeler mouse, in which the gene encoding Reln

Received Aug. 9, 1999; revised Nov. 30, 1999; accepted Dec. 2, 1999.

G.M. is supported by Grant PB 97-0582-CO2-02, Ministerio de Educación y Cultura, Spain. Work in the laboratory of A.M.G. is supported by Grants Action de Recherches Concertées 186, Fonds de la Recherche Scientifique Médicale 3. 4544.95, and Fondation Médicale Reine Elisabeth, all from Belgium. We thank Victoria Bello for technical assistance and José Antonio Ayala for excellent photographic work. We are grateful to Paula Plaza for help with Figure 6.

Correspondence should be addressed to Gundela Meyer, Department of Anatomy, Faculty of Medicine, University La Laguna, 38071 La Laguna/Tenerife, Spain. E-mail: gmeyer@ull.es.

Copyright (C) 2000 Society for Neuroscience $\quad 0270-6474 / 00 / 201858-11 \$ 15.00 / 0$ stage 21 and inserts itself within the pioneer plate, which is thus split into a minor superficial component and a larger deep component that presumably corresponds to the subplate. Initial CP neurons are radially organized and mostly CR-negative. Reln-positive cells remain consistently segregated from the pioneer cells and are thus not directly involved in preplate partition. Our data indicate that the neuronal composition of the human neocortical preplate is more complex than generally described and that various neurons participate in a sequence of events that precede the emergence of the CP.

Key words: Cajal-Retzius cells; preplate; marginal zone; subplate; reelin; neuronal migration

is defective, the preplate fails to split into MZ and subplate, and the normal migration gradient is inverted (Caviness, 1982; Goffinet, 1984; Sheppard and Pearlman, 1997).

Our previous work on rat cortical development suggested that this view may be an oversimplification in that the cellular composition of the preplate is more complex than usually recognized (Meyer et al., 1998). A transient cell type in the MZ contributing early efferent projections was named "pioneer neuron" of the developing cortex. Pioneer neurons were born before most Relnproducing Cajal-Retzius cells, which are thought to represent the oldest neuron of the cortex (Marín-Padilla, 1998). Furthermore, Cajal-Retzius cells were shown to have multiple origins. Although some were present as early as E12, other similar neurons were added later, through a rudimentary subpial granular layer (SGL).

The events that control development of the embryonic human cortex are even less well known. In a previous paper (Meyer and Goffinet, 1998) we showed that the human SGL supplies the growing MZ with Reln-immunoreactive Cajal-Retzius-like neurons during the period of cortical plate migration, which complement early-born Cajal-Retzius cells. We focused on the period after the emergence of the cortical plate and did not address the origin of human preplate neurons.

In the present work we describe the events that precede and accompany the initial formation of the human cortical plate. By using immunohistochemistry for Reln, calretinin (CR), and glutamic acid decarboxylase (GAD), we sought to define the origin of the earliest Reln-producing cells and to search for the possible existence of a human homolog of the rat pioneer neurons.

\section{MATERIALS AND METHODS}

Human embryonic brains were obtained after legal abortions, following national guidelines in Spain and Belgium and in accord with the competent medical ethics committees in our institutions. In addition, fetal 
brains were obtained after spontaneous abortions, under the same ethical guidelines.

We examined 10 embryonic and early fetal human brains. The embryonic material, 5-7 gestational weeks ( $\mathrm{GW}$ ) old, was classified on the basis of external morphology and brain features, according to the Carnegie stages (O'Rahilly and Müller, 1994). The age of the fetuses was inferred from the gestational history, as indicated by the obstetrician. One case of each of the following stages was examined (approximate gestational age in brackets): 15 (4.5 GW); 16 (5 GW); 16/17 (5.5 GW); 17 (6 GW); 17/18 (6 GW); 18 (6.5 GW); 19 (6.5 GW); 20 (7 GW); 21 (7 GW); 22 (8 GW). The whole heads or, in the fetuses, the brains, were fixed in Bouin's fixative, embedded in paraffin, and cut in series of $10-\mu \mathrm{m}$-thick sections, in a coronal or parasagittal plane. Two cases (stages 17 and 21) were fixed in $4 \%$ paraformaldehyde.

For immunohistochemistry, sections were incubated in the primary antibodies overnight in a humid chamber. After rinsing, they were incubated in the corresponding biotinylated secondary antibodies, rabbit anti-mouse IgG or goat anti-rabbit IgG (Dako, Glostrup, Denmark), diluted 1:200 in Tris-buffered saline (TBS), washed, and incubated in the $\mathrm{ABC}$ complex (Dako). Bound peroxidase was revealed using 0.05\% 3, 3'diaminobenzidine tetrahydrochloride (DAB; Sigma, St. Louis, MO) $0.06 \%$ ammonium nickel (II) sulfate (Sigma), and $0.01 \%$ hydrogen peroxide in TBS. The sections were dehydrated, cleared, and mounted with Eukitt (O. Kindler GmbH, Freiburg, Germany). The primary antibodies were a polyclonal antibody raised in rabbit against human CR (1:3000) (SWant, Bellinzona, Switzerland), a polyclonal antibody raised in rabbit against GAD 65 and 67 (1:1000) (Chemicon, Temecula, CA), and a mouse monoclonal anti-reelin antibody 142 (de Bergeyck et al., 1998). Method specificity was controlled by omitting the primary antibodies.

Double-label immunocytochemistry was performed to visualize the association between Reln and CR, and Reln and GAD, in the same section. After the first primary antiserum (anti-reelin 142 diluted 1:500), sections were incubated in the corresponding anti-mouse secondary antibody and processed with DAB and ammonium nickel sulfate as described above, which yielded a black reaction product. After thorough rinses, the sections were then incubated overnight in the second primary antibody CR, 1:3000, or GAD, 1:1000. The secondary antibody was in this case the corresponding goat anti-rabbit IgG. After washing, the sections were immersed in $0.005 \%$ DAB with $0.0001 \%$ in $0.05 \mathrm{M}$ Tris buffer, $\mathrm{pH} 7.8$; the reaction product appeared brown.

Selected sections of the stage- 19 case were microwaved for $1 \mathrm{~min}$ on full power in citrate buffer at pH 2.5 (Evers and Uylings, 1994). This treatment enhanced Reln immunoreactivity without affecting the staining pattern, although it slightly increased background (see Fig. 2, compare $A-C$, with microwave treatment, with $D, E$, without treatment).

\section{RESULTS}

Observations will be described by following the Carnegie stages as defined by O'Rahilly and Müller (1994), beginning with stage 16 , corresponding to $\sim 5 \mathrm{GW}$, up to stage $22(\sim 8 \mathrm{GW})$.

For most authors, the term preplate implies the presence of an early external layer containing at least two cell populations that are subsequently split into MZ cells, usually defined as CajalRetzius cells, and subplate neurons, by the first cohorts of the cortical plate (CP) (Rickmann and Wolff, 1981; Allendoerfer and Shatz, 1994; Pearlman et al., 1998; Supèr et al., 1998 MarínPadilla, 1998). Accordingly, we use the term "marginal zone" (MZ) for the first stages of human corticogenesis, when the only differentiated elements are Reln-immunoreactive (ir) neurons, and we reserve the term "preplate" for later stages when Relnnegative putative subplate neurons have appeared.

\section{Stages 16-18, early marginal zone}

The first Reln-expressing cells were observed at stage 16 (5 GW) as a few neurons scattered below the pial surface in the lateral aspect of the cortical wall corresponding to the presumptive neocortex (Fig. 1A). They increased in density from stages 16 to $17(6 \mathrm{GW})$, and occasionally they were also observed within the VZ (Fig. 1B). At stage 17, they formed a continuous row of nearly horizontal neurons in the narrow (10-15 $\mu \mathrm{m}$ width) MZ (Fig.
1C). At stage $18(6.5 \mathrm{GW})$, the $\mathrm{MZ}$ was wider $(30-50 \mu \mathrm{m})$ and contained Reln-ir neurons at different stages of differentiation and located at variable distances from the pial surface (Fig. 1D). The more mature-looking neurons were horizontally arranged and extended prominent processes. Smaller rounded cells, apparently less mature, lay closer to the ventricular zone. At this stage, very few neurons occupied an immediate subpial position. At stages 17 and 18, the packing density of Reln-ir neurons was higher rostrally (Fig. $1 E$ ) than caudally (Fig. $1 F$ ). At these early stages, a few radially oriented columns of Reln-ir cells were present in the VZ (Fig. 1E). CR and GAD were not yet expressed by neurons in the neocortical anlage.

\section{Stage 19, preplate}

At stage $19(6.5 \mathrm{GW})$, CR-ir cells appeared for the first time in the MZ, which from this moment might be considered the preplate, and were particularly numerous at rostral levels (Fig. $2 F, G)$. CR-ir cells in the superficial ventricular zone were continuous with aggregates of similar CR-ir neurons in the preplate, some of which assumed a horizontal orientation. In a few places, CR-ir cells were also observed deeper in the VZ (Fig. 2G). Reln was expressed by numerous neurons in the rostral preplate. Columns of Reln-ir cells spanning almost the entire width of the neuroepithelium were particularly prominent in the rostral cortical wall (Fig. $2 A-E$ ), where they were quite regularly spaced at intervals of $\sim 75-150 \mu \mathrm{m}$. Whereas Reln-immunoreactivity was weak in cells in the lower tiers of the VZ (Fig. 2D,E), it increased as the cells approached the preplate (Fig. 2B,C). Reln-ir and CR-ir neurons lay intermixed in the preplate, without any apparent lamination. The preplate of the presumptive caudal neocortex was narrow and contained only a few immature Reln- and CRexpressing neurons. In the relatively more mature lateral part of the cortical wall, the first GAD-ir neurons appeared in the IZ but not yet in the preplate.

\section{Stage 20, the monolayer}

Whereas at stage 19 the neocortical preplate was characterized by a diffuse and apparently random arrangement of CR-ir and Reln-ir neurons, stage $20(7 \mathrm{GW})$ marked the beginning of its compartmentalization. A loosely organized single layer of horizontally oriented CR-ir cells, referred to below as the monolayer, appeared at an approximate distance of $20-30 \mu \mathrm{m}$ from the pial surface all over the cortical wall (Figs. 3A, 4A). The largest neurons (long diameter $10-15 \mu \mathrm{m}$ ) had a bipolar shape; one of the processes often displayed the fine caliber of an axon, whereas the other was thicker and presumably represented a dendrite. A rather elaborate dendritic branching pattern indicated advanced differentiation (Fig. 3B). In addition, smaller (7-10 $\mu \mathrm{m})$ and more rounded, apparently more immature neurons contributed to the monolayer. At less mature dorsal and caudal levels, the monolayer was discontinuous, and CR-ir cells had a more irregular distribution. GAD staining revealed similar cells with a similar distribution (Fig. 4B). Although double-labeling GAD-CR could not be performed, the morphology of the neurons and their distance from the pia suggested at least partial colocalization of both antigens in the neurons of the monolayer (Fig. 4, compare $A$ and $C$ with $B$ and $D$ ). However, not all neurons were CR-ir or GAD-ir, suggesting the possibility of yet other cell populations. Double-labeling experiments of CR-Reln and GAD-Reln showed that neurons in the monolayer did not express reelin (Fig. $4 A-D)$.

With the appearance of the monolayer, Reln-ir cells shifted 

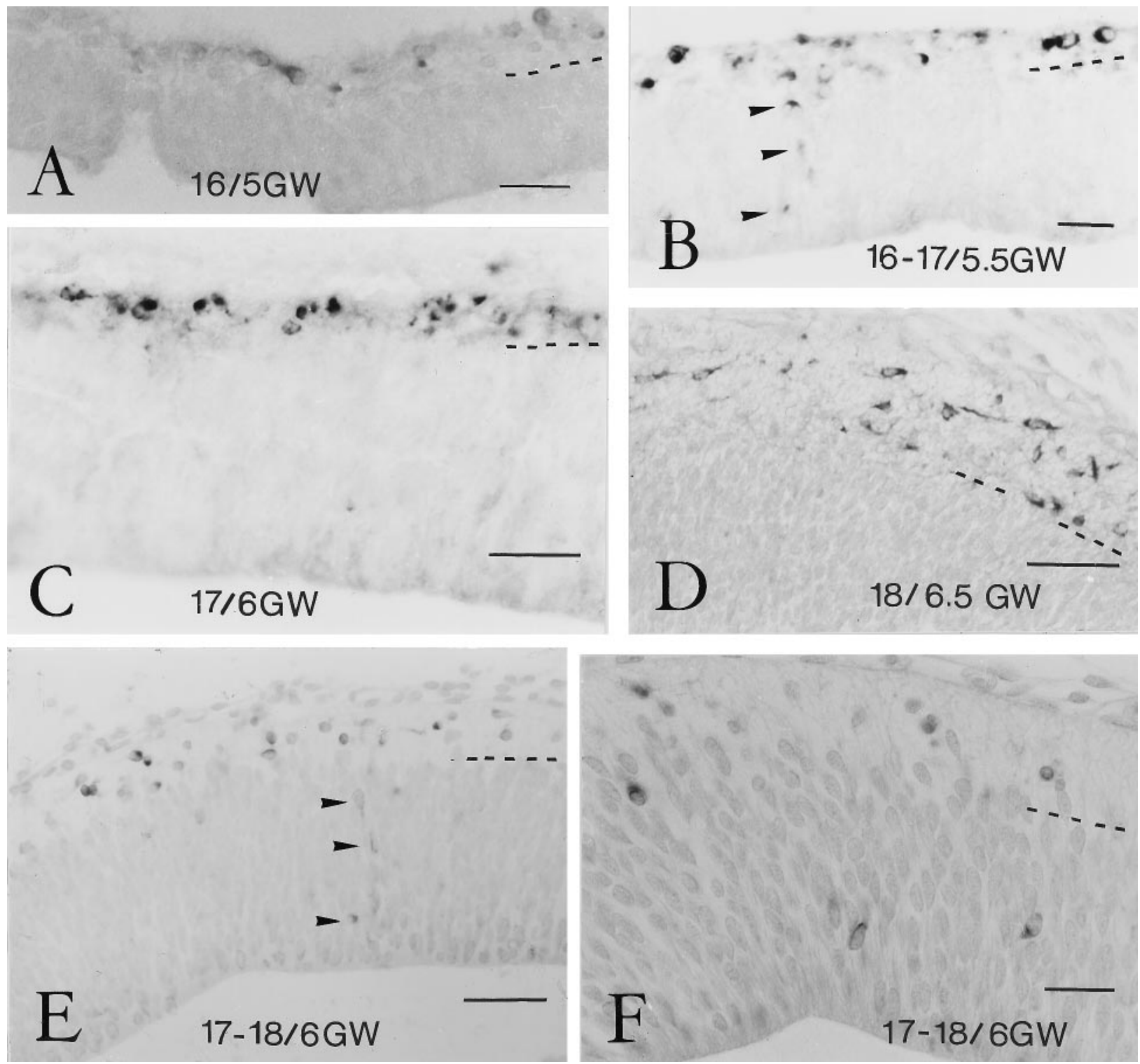

Figure 1. Reelin in early marginal zone. A, Stage 16,5 GW. The first Reln-ir neurons appear at the outer aspect of the prospective neocortical neuroepithelium, in a narrow cell-sparse MZ. In this and the following microphotographs, the dashed line marks the border of the MZ and VZ. Scale bar, $25 \mu \mathrm{m}$. B, Stage 16/17, 5.5 GW. The VZ occasionally contains weakly Reln-ir cells (arrowheads), which seem to ascend to the MZ. Scale bar, $25 \mu \mathrm{m}$. $C$, Stage 17, $5.5 \mathrm{GW}$. Reln-ir neurons in the MZ increase in number. Scale bar, $50 \mu \mathrm{m}$. $D$, Stage 18, $6.5 \mathrm{GW}$. In rostral cortical areas, Reln-ir neurons lie now at different distances from the pial surface. Scale bar, $50 \mu \mathrm{m}$. E. Stage 17/18, $6 \mathrm{GW}$. In addition to Reln-ir neurons in the MZ, a few weakly immunostained cells (arrowheads) are present in the VZ, arranged into columns. Scale bar, $50 \mu \mathrm{m}$. F, Same case as in $E$, at a more caudal level, where Reln-ir neurons in the MZ are less numerous. Note positive cells in the deep VZ. Scale bar, $25 \mu \mathrm{m}$.

into a subpial position and became clearly segregated from the deeper horizontal neurons (Figs. $3 D, 4 A-D$ ). Only in the dorsal and caudal regions were reelin-ir neurons also located at deeper levels of the preplate, although the more differentiated neurons occupied more superficial positions than smaller, more immature cells that lay near the VZ. In the most mature part of the prospective neocortex, i.e., the lateral field facing the lateral ganglionic eminence, a new type of more rounded neurons, the pioneer cells, began to aggregate below the monolayer neurons (Figs. $3 C, 4 A)$. Pioneer neurons will be described in more detail below; at stage 20, their descending axons were not easily identified .

\section{Stages 21 and 22, pioneer plate and cortical plate}

The most significant change at stages 21 and $22(7-8 \mathrm{GW})$ was the emergence of the CP. This key event was accompanied by the appearance of new neuronal types and preceded by the formation of a transient cell condensation, the pioneer plate. The most prominent cell type of the pioneer plate was a strongly CRpositive but GAD- and Reln-negative neuron, the axon of which coursed into the IZ and gave rise to early efferent connections of the cortex (Fig. 5G). Accordingly, we considered this cell type the pioneer projection neuron of the human cortex. Although, as mentioned above, the first pioneer cells were already observed in the most differentiated ventrolateral cortex at stage 20, at that moment their axons were only short processes that did not exceed $20 \mu \mathrm{m}$.

The pioneer plate was prominent at stage 21, when large numbers of pioneer neurons settled at the inner aspect of the monolayer, which thus became less distinct. In the relatively more 

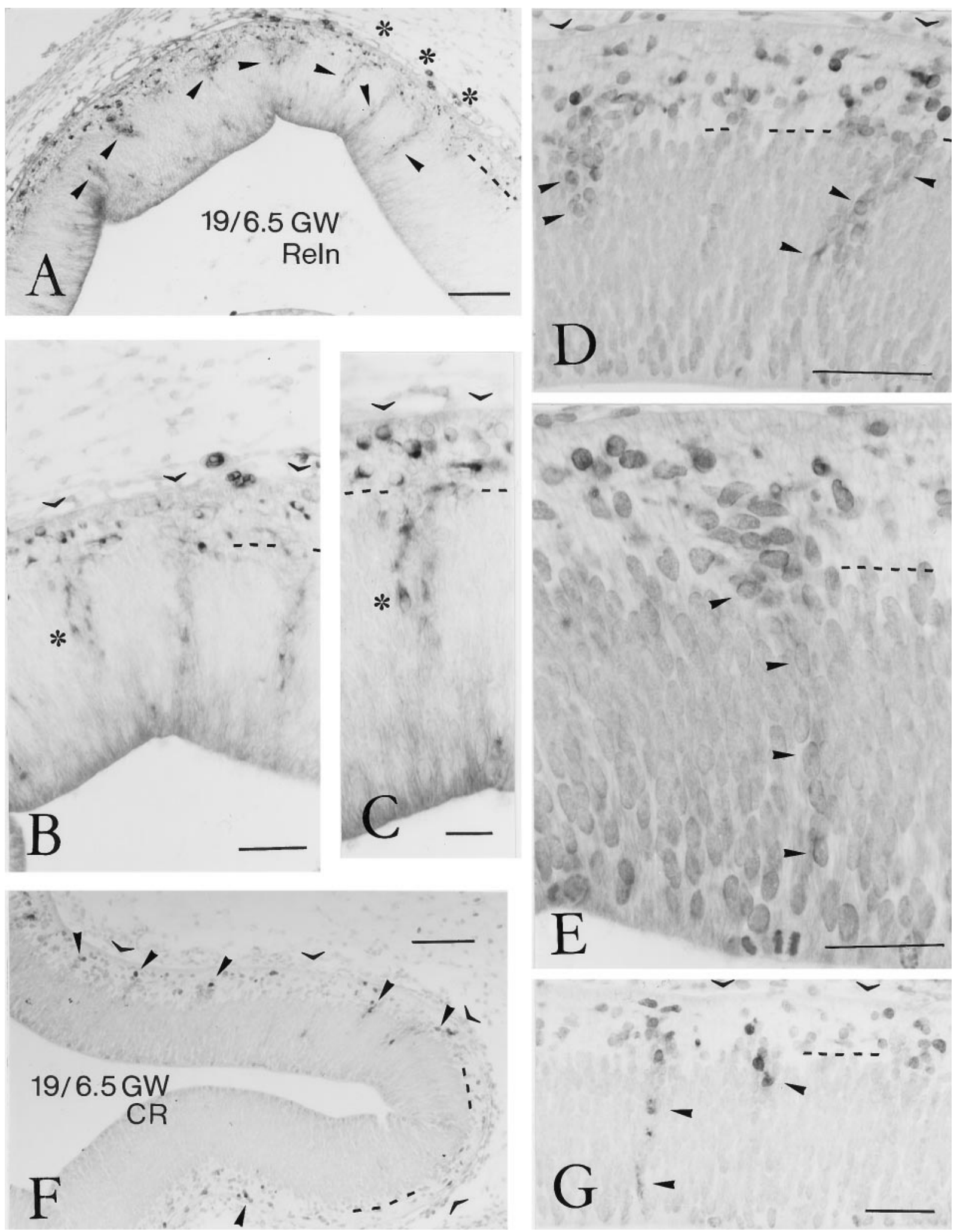

Figure 2. Reelin- and calretinin-ir neurons in the human preplate at stage 19, $6.5 \mathrm{GW}$. A, Low-power view of the rostral neocortex, immunostained for Reln. Arrowheads point to aggregates of Reln-positive cells in the VZ that seem to ascend to the preplate. Dashed line indicates border between VZ and preplate. Asterisks mark three radial columns of Reln-ir neurons in the VZ. Scale bar, $100 \mu \mathrm{m}$. B, Higher-power view of radial columns of Reln-ir neurons in the VZ. Open arrowheads indicate the pial surface, at places obscured by connective tissue. Scale bar, $50 \mu \mathrm{m}$. $C$, Higher magnification of the cell column marked by an asterisk in $B$ and $C$, showing clearly the Reln immunoreactivity, which increases in intensity from the VZ to the preplate. Scale bar, $25 \mu \mathrm{m}$. $D$, Two Reln-ir cell aggregates (arrowheads) in the upper VZ, in continuity with Reln-positive neurons in the preplate. Scale bar, $80 \mu \mathrm{m}$. $E$, A single column of weakly Reln-ir cells (arrowheads) spans almost the entire width of the VZ. Scale bar, $40 \mu \mathrm{m}$. F, At stage 19, calretinin-ir (CR) neurons appear for the first time in the prospective neocortex, marking the beginning of the preplate period. Arrowheads point to aggregates of CR-ir neurons in the preplate. Scale bar, $100 \mu \mathrm{m}$. $G$, Occasionally, CR-ir cells are present in the VZ. Scale bar, $50 \mu \mathrm{m}$. 

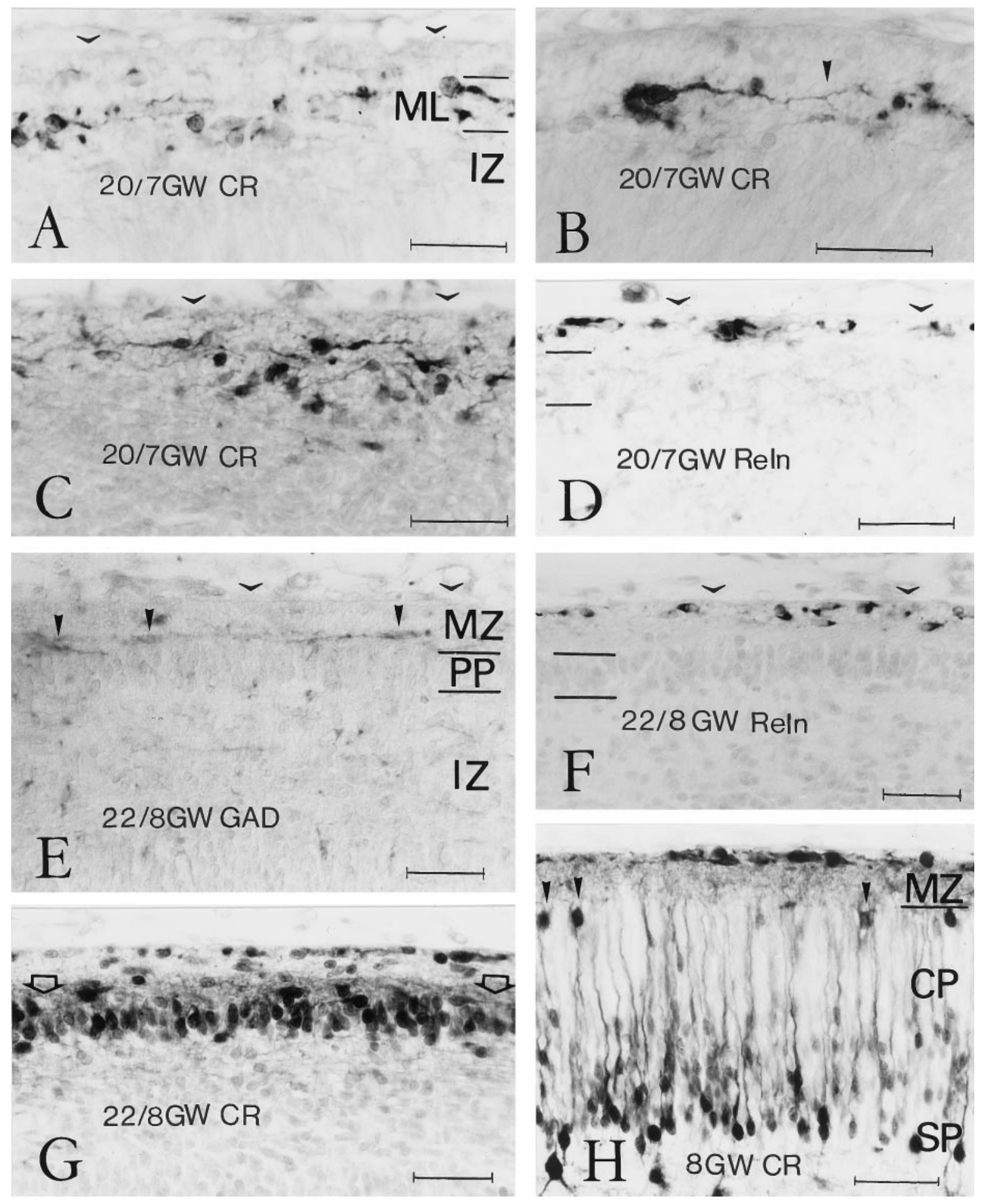

Figure 3. Cell populations in preplate, pioneer plate, and cortical plate. $A-D$, Stage 20,7 GW. $A$, A loosely organized layer of mostly horizontal calretinin $(C R)$-ir neurons, referred to as the monolayer $(M L$, between the two parallel lines), appears in the preplate, superficial to the intermediate zone (IZ). Scale bar, $40 \mu \mathrm{m}$. B, Large neurons in the monolayer are strongly CR-ir and display a differentiated dendritic branching pattern. Arrowhead points to a dendritic ramification. Scale bar, $35 \mu \mathrm{m}$. $A$ and $B$ are from the dorsolateral cortical wall. $C$, In the more mature ventrolateral cortex, other CR-ir neurons begin to assemble at the inner aspect of the monolayer. Scale bar, $40 \mu \mathrm{m}$. $D$, An adjacent section, immunostained for Reln, shows that the neurons in the monolayer (between the parallel lines) do not express Reln, but that Reln-ir neurons are confined to an immediate subpial compartment (open arrowheads mark the position of the pial surface). Scale bar, $40 \mu \mathrm{m}$. $E-H$, Stage $22,8 \mathrm{GW}$. E-G, Adjacent sections of the dorsal neocortex, a level where the pioneer plate $(P P)$ is just segregating, immunostained for GAD $(E)$, Reln $(F)$, and $\mathrm{CR}(G)$. E, Horizontal GAD-ir neurons (solid arrowheads) lie immediately above the PP, in the deep tiers of the marginal zone $(M Z)$, whereas the Reln-ir cell layer $(F)$ has a subpial position. $G$, Neurons in the PP are strongly CR-positive. Open arrows indicate a strongly CR-ir plexus just above the PP. H, CR-stained section in the ventrolateral neocortex, where the cortical plate $(C P)$ has split the PP into a superficial (solid arrowheads) and a deep contingent. Deep pioneer neurons, presumably representing the subplate $(S P)$, assume a pyramidal shape but display a more differentiated dendritic branching pattern than CP neurons. CR is now strongly expressed by cells in the subpial compartment. Scale bars $(E-H): 50 \mu \mathrm{m}$. 

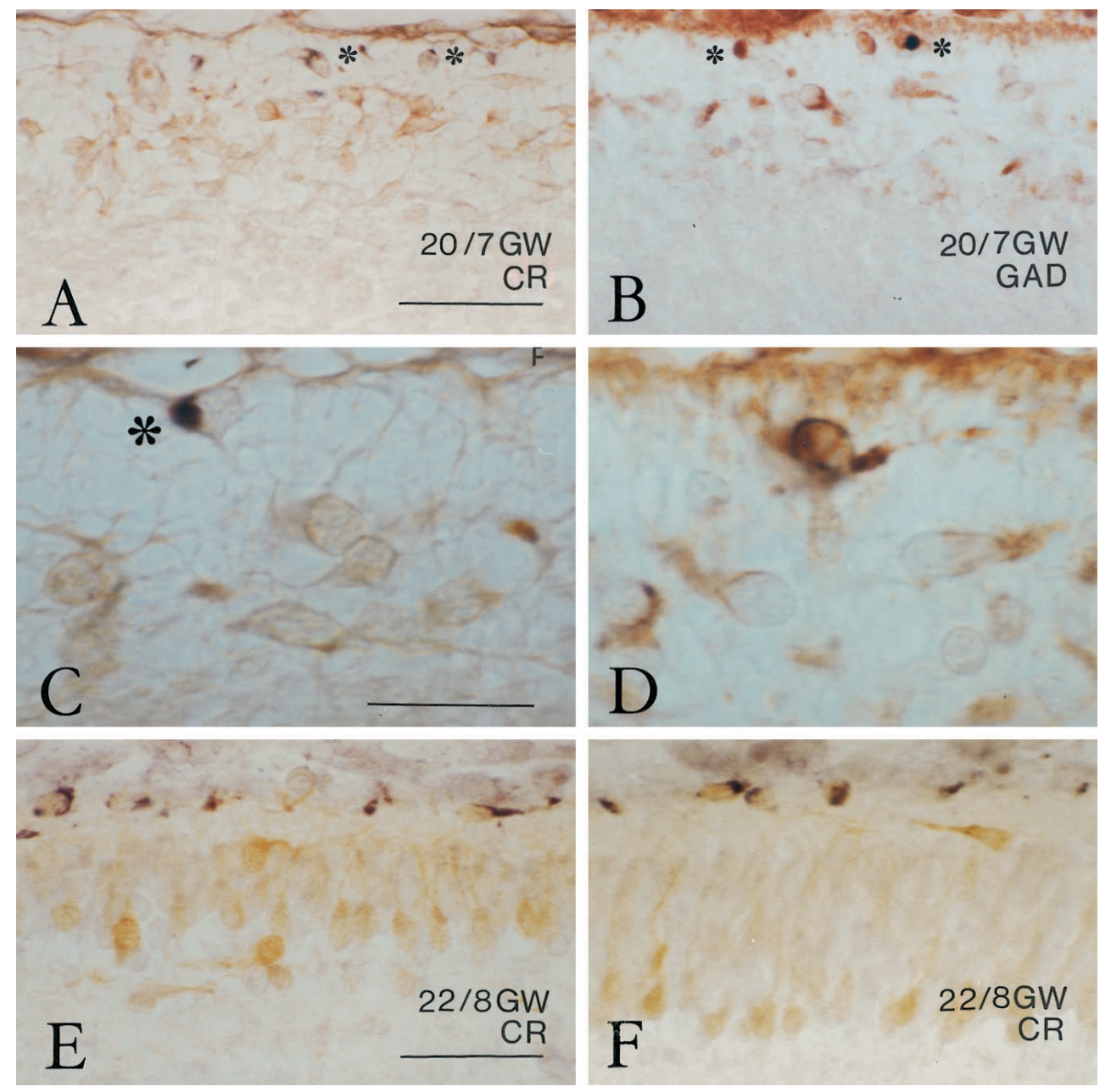

Figure 4. The segregation of the subpial Reln-compartment. $A-D$, Stage 20, 7 GW. $A$ and $C$ are double-labeled with Reln (black, asterisks) and CR (light brown); $B$ and $D$ show Reln (black, asterisks in $B$ ) and GAD (brown). Horizontal neurons in the monolayer express CR and/or GAD but are Reln-negative. From stage 20 onward, Reln is mostly expressed by subpial neurons and only occasionally by deeper ones. The apparently Reln-negative subpial neuron in $B$ showed traces of immunoreactivity in another focal plane. The Reln-ir neuron in $C$ (asterisk) is immediately attached to the pial surface. Scale bars: $A, B, 50 \mu \mathrm{m}$; $C, D, 25 \mu \mathrm{m}$. $E, F$, Stage 22, $8 \mathrm{GW}$. Double-immunostaining of Reln (black) and CR (light brown) demonstrates the segregation of subpial Reln compartment and cortical plate. Occasional horizontal neurons just above the cortical plate are Reln-negative. $E$ is from the dorsolateral neocortex; $F$ is from a slightly more ventral area. Scale bars: $E, F, 50 \mu \mathrm{m}$. immature dorsal and caudal regions of the cortical wall (Fig. 5A), the pioneer plate was formed by two or three cell rows that were continuous with the horizontal cells of the monolayer, still present in the medial cortical wall. Horizontal cells were also observed in the superficial tier of the pioneer plate (Fig. $5 A$ ), whereas the pioneer neurons were more rounded. The pioneer plate gradually increased in thickness in more lateral regions, where it comprised four to seven cell rows (Fig. 5D). In the developmentally more advanced ventrolateral cortex, the pioneer plate became invaded by another population of GAD-negative, CR-negative, or weakly positive neurons. This step, the partition of the pioneer plate by the first cohorts of the cortical plate, was initiated at stage 21 and continued into stage 22 .

At stage $22(8 \mathrm{GW})$, the pioneer plate was recognizable in the dorsal cortex as a compact aggregate of intensely CR-positive neurons (Figs. 3G, 5G), which resembled the lateral pioneer plate of stage 21 but in addition displayed signs of a more advanced cytological differentiation, such as a slightly more vertical orientation in the deeper tiers and a more triangular soma shape and emission of oblique dendrites in the upper tier (Fig. 5G,H, arrowheads). The descending axons were now clearly visible in the IZ as a CR-ir fiber tract (Fig. 5G, small arrows). The radial disposition of the deep pioneer plate component was progressively more accentuated in intermediate and lateral cortical areas, where they assumed a pyramidal shape with a prominent apical dendrite (Fig. $5 H-J)$. Concurrently, the deep and superficial contingents of the pioneer plate became more and more separated through the interposition of another population of initially moderately CRpositive (Fig. 5H,I) and later CR-negative neurons (Fig. 5J), which we interpreted as the first cohorts of the CP. The superficial pioneer cells appeared increasingly spaced from medial to lateral (compare Fig. $5 H-J$ with Fig. $4 H$, from the most differentiated ventrolateral level of the same case), indicating that no further members were added to this early cell population.

The nonradial condensation of pioneer cells into a pioneer plate might be interpreted as a preliminary step before the formation of the $\mathrm{CP}$. The radially arranged CR-negative neurons would then correspond to the first representatives of the cortical plate proper, which divide the pioneer plate into a superficial and a deep part. The deep pioneer plate component would represent the subplate (Fig. 5I,J, SP), or presubplate following the terminology of Kostovic and Rakic (1990).

During the process of pioneer plate formation, we consistently observed horizontally elongate or rounded GAD-positive neurons concentrated mostly at the external border of the pioneer plate (Fig. $5 B, E$ ); they resembled the neurons of the former monolayer. In the more differentiated stage 22, GAD-ir neurons extended long horizontal processes along the upper border of the pioneer plate (Fig. 3E). Comparison with adjacent sections stained for Reln (Fig. $3 F$ ) and CR (Fig. 3G) showed that the GAD-expressing neurons lay below the Reln-positive subpial compartment, at a level immediately above the pioneer plate, filled with a dense CR-ir plexus (Fig. 3G, open arrows).

At stages 21 and 22, Reln-ir neurons remained arrayed into a 

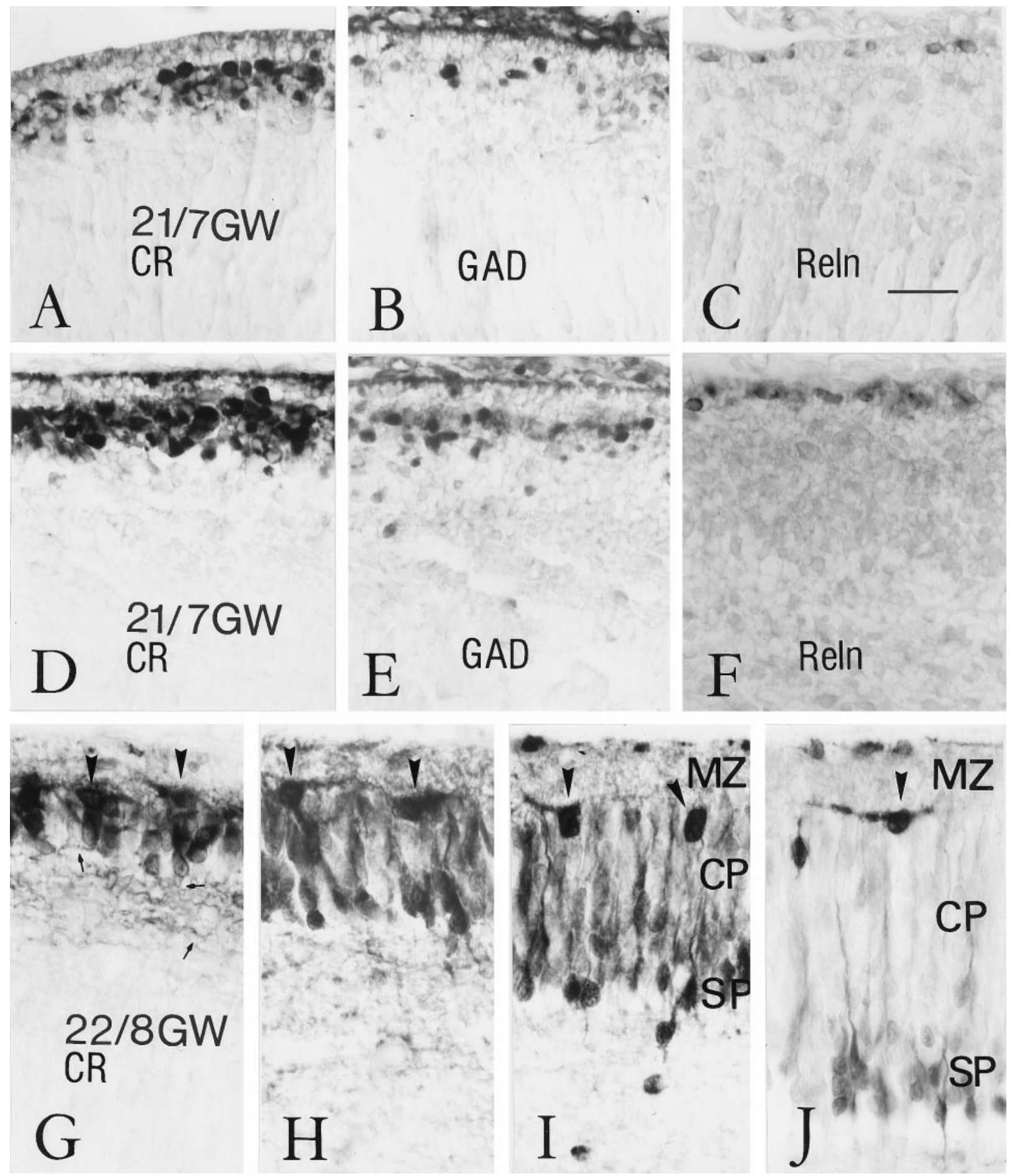

Figure 5. Partition of the pioneer plate and establishment of the cortical plate. $A-F$, Stage $21,7 \mathrm{GW}$. $A-C$, Sections from the more immature dorsal cortex at stage 21, stained for $\mathrm{CR}(A), \mathrm{GAD}(B)$, and Reln $(C) . A$, The pioneer plate, populated with intensely CR-ir neurons, is thin and contains many superficial horizontal cells, which resemble those of the monolayer at stage 20. B, GAD-ir neurons are less abundant than CR-ir cells and concentrated at the level of the superficial pioneer plate. $C$, Reln-ir neurons are located immediately below the pia. $D-F$ are from the relatively more mature lateral cortex, stained for CR $(D)$, GAD $(E)$, and Reln $(F)$. $D$, The lateral pioneer plate consists of several rows of densely aggregated, intensely CR-positive neurons that lack a radial orientation. $E$, GAD-ir neurons are less numerous than those expressing CR and more abundant in the external aspect of the pioneer plate. $F$, Reln is expressed specifically by cells in the subpial compartment. $G-J$, Stage $22,8 \mathrm{GW}$, immunostained for CR. There is a gradual splitting of the pioneer plate from the most dorsal $(G)$ to intermediate $(H, I)$ and more lateral $(J)$ levels. $G$, A pioneer plate stage similar to that shown in $D$, with the difference that an incipient radial cell orientation is now evident, as well as the presence of a fiber tract (small arrows point to axons). $H-J$, At progressively more lateral levels, the intensely CR-positive pioneer neurons become more and more separated into a superficial population (arrowheads) and a deep, radially oriented population that presumably represents the subplate $(S P)$. The cortical plate $(C P)$ consists of initially moderately CR-positive and later CR-negative neurons that become inserted within the pioneer plate. All microphotographs were taken at the same magnification. Scale bar (shown in $C$ ): $25 \mu \mathrm{m}$. Case 21, showing less perfect tissue preservation, could have undergone more retraction during histological procedures. 

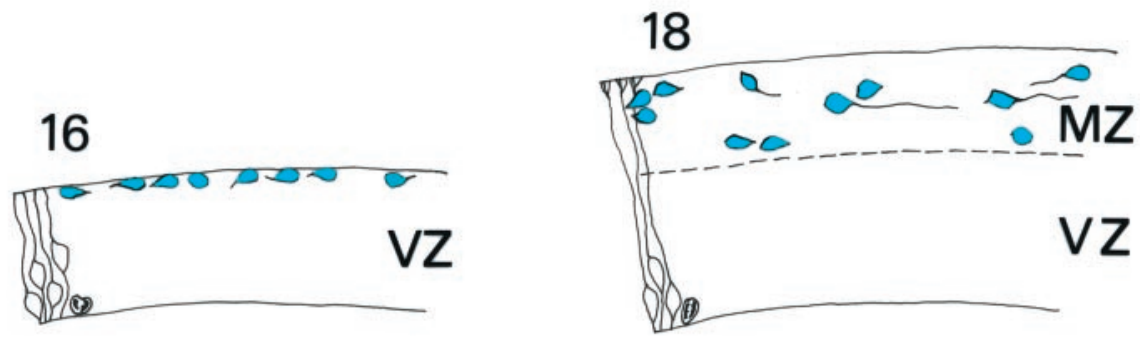

19
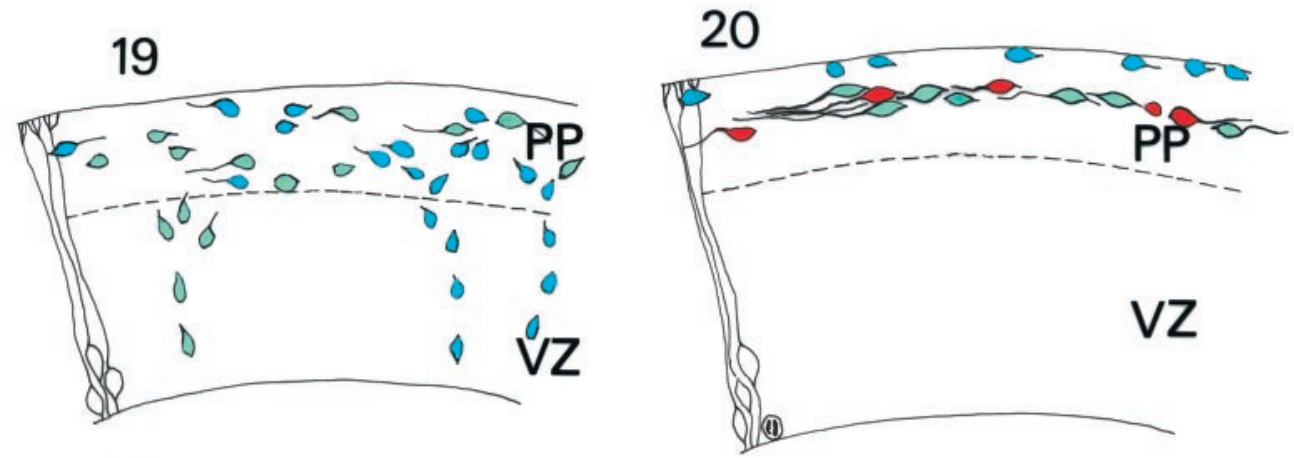

21

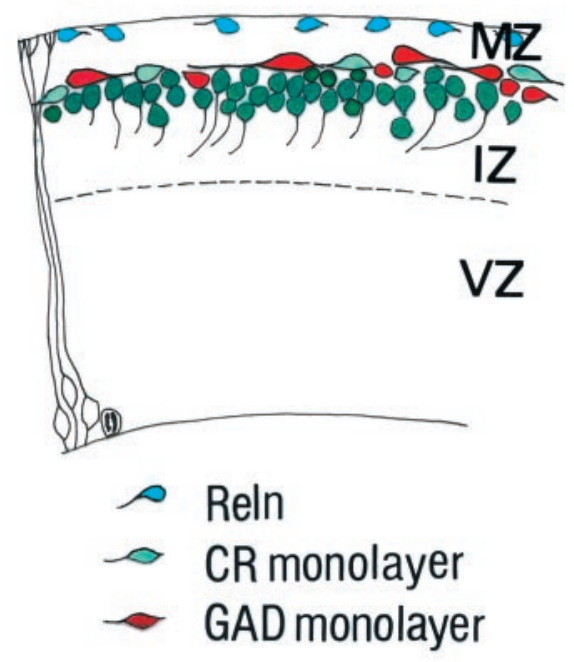

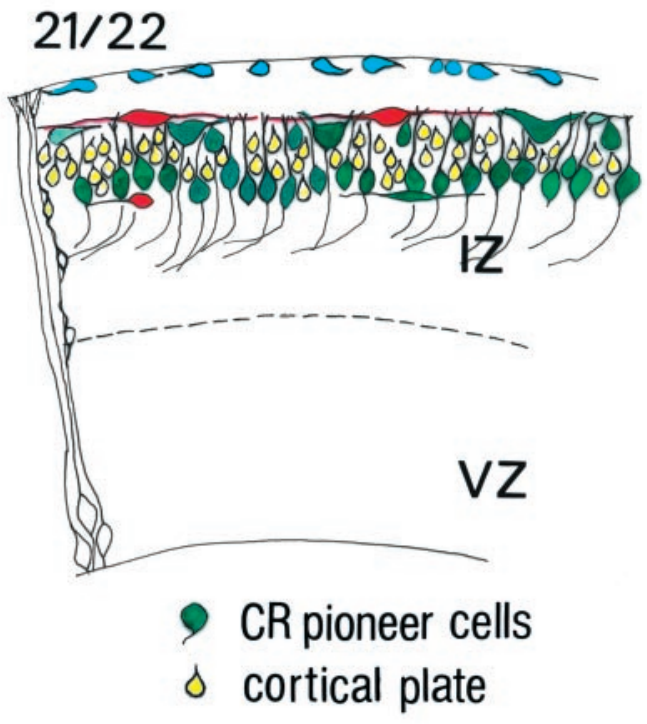

Figure 6. Diagrammatic representation of the developmental events proposed in this study, from stage 16 to stage 22. All figures were drawn at the same magnification with the aid of a camera lucida. Blue, Reln; light green, early CR-ir neurons in the monolayer; red, GAD; dark green, pioneer cells; yellow, cortical-plate neurons. The first Reln-ir neurons appear at stage 16 , in a narrow MZ, and increase in number from stages 17 to 19 . The first CR-ir neurons appear at stage 19 in what could now be called the preplate. Together with GAD-ir neurons, which appear at stage 20, they form the monolayer within the preplate. Concurrently, Reln-ir neurons settle in the subpial compartment. At stage 21 , the pioneer plate aggregates below the monolayer and sends the first corticofugal fibers. The pioneer plate is split apart into a minor superficial component and a large deep component (the subplate) through the first cohorts of the cortical plate, at stages 21 and 22. In this scheme, possible colocalizations have not been taken into account. $I Z$, Intermediate zone; $M Z$, marginal zone; $P P$, preplate; $V Z$, ventricular zone. single subpial row, separated from pioneer and cortical plates by a cell-sparse marginal zone $\sim 15 \mu \mathrm{m}$ wide (Figs. $3 F, 4 E, F, 5 C, F$,). Only occasionally did we observe a small Reln-ir neuron deeper in the MZ, most commonly in the less mature cortical regions.

With increasing differentiation of the $\mathrm{CP}, \mathrm{CR}$ expression became more prominent in subpial Reln-ir neurons (Fig. $3 H$ ). The further development of Cajal-Retzius cells/Reln-expressing neurons of the human MZ has been described previously (Meyer and Gonzalez-Hernandez, 1993; Meyer and Goffinet, 1998) and will thus not be considered here.

\section{DISCUSSION}

The mechanisms that control early cortical development remain poorly understood. A general consensus holds that an early cellular compartment, the preplate, is split into the MZ containing Cajal-Retzius cells and subplate (Marín-Padilla, 1971, 1972). Numerous birthdating experiments confirmed the partition of early-born preplate neurons (Raedler and Raedler, 1978; Kos- tovic and Rakic, 1980; Luskin and Shatz, 1985; Chun and Shatz, 1989; Wood et al., 1992). Thus far, however, the cellular identity of the preplate components has not been fully defined in human cortex.

Our data show that the initial formation of the human cortex is a complex process that involves several neuronal populations. Some of these cell classes have not been described previously, possibly because the rodent and carnivore cortices on which the currently prevailing concepts are founded do not provide the necessary temporospatial resolution. We suggest the following sequence of events (Fig. 6). The first step is the appearance of Reln-expressing neurons along the outer aspect of the neuroepithelium and the establishment of a cell-sparse MZ (stages 16-18). This is followed by the formation of a monolayer of horizontal, CR- and/or GAD-positive neurons, concurrent with the segregation of a Reln-positive subpial cell compartment (stage 20). A third event is the condensation of a "pioneer plate" populated by 
CR-positive, GAD-negative pioneer cells (stage 21). The fourth stage corresponds to the appearance of the $\mathrm{CP}$ proper within the framework of the pioneer plate (stages 21-22). Early cortical development is thus characterized by continuous changes involving neuronal populations that cannot be simply defined in terms of Cajal-Retzius cells and subplate.

\section{Reelin-expressing cells}

Reln-expressing neurons are the only postmitotic cell population in the neocortical anlage during stages 16-18; they increase in number while the cortical wall grows. The presence of radial columns of Reln-ir neurons traversing the ventricular zone suggests a local origin, as described for Reln-producing cells in the mouse (Alcántara et al., 1998). However, local origin and radial migration do not exclude the possibility that Reln-ir neurons move tangentially in $\mathrm{MZ}$ and preplate. Indeed, their monopolar morphology, horizontal orientation, and prominent leading processes are strongly reminiscent of tangentially migrating neurons (Austin and Cepko, 1990; O'Rourke et al., 1992, 1995). In addition, we cannot rule out that some Reln-ir neurons invade the preplate tangentially from noncortical sources such as the medial ganglionic eminence, which is known to produce Reln-ir CajalRetzius cells in the rodent (Lavdas et al., 1999). At later stages, after the emergence of the CP, further populations of Reln-ir neurons are added to the MZ by longer distance tangential migration from the periolfactory basal forebrain through the SGL (Meyer and Goffinet, 1998; Meyer and Wahle, 1999). During a protracted period, from $5 \mathrm{GW}$ to midgestation, Reln-ir neurons with different morphological and neurochemical profiles are thus continuously delivered into preplate and MZ through both radial and tangential migration. As a corollary, the definition of Relnproducing Cajal-Retzius cells as the earliest-born cell class of the cerebral cortex is misleading.

\section{Horizontal monolayer cells}

At stages 19/20, around 7 GW, a new cell type appears as a CRand/or GAD-positive, but Reln-negative neuron disposed horizontally in a single layer. Although this layer is sometimes discontinuous or the cells may be aligned in two rows, the overall impression is clearly that of a single, loosely organized layer in which the dominant cell type is the horizontal neuron. The colocalization of $\mathrm{CR}$ and GAD in these neurons needs to be explored further, although similar morphology and location suggest substantial overlap. In parallel to the formation of the monolayer, Reln-ir elements shift into a subpial position and are no longer seen in intermediate zone and lower preplate.

The horizontal CR/GAD-ir neurons may define a new step in cortical development. They appear before the pioneer cells and may be important for the unfolding of subsequent events. Preliminary evidence (G. Meyer, unpublished observations) shows that they also express the disabled-1 (Dab1) protein and are thus presumably responsive to the Reln signal (Cooper and Howell, 1999). This differential expression of Reln and Dab1 may explain why Reln-ir neurons are segregated from the monolayer. The GAD-ir neurons in the monolayer are possibly identical with the GABA-positive cells described by Zecevic and Milosevic (1997). We show here that they are Reln-negative, although their morphology strongly resembles that of Cajal-Retzius cells of classical Golgi studies. However, some GAD-ir neurons in the rodent preplate may also express Reln (Meyer et al., 1998; Lavdas et al., 1999) and can thus be considered a subpopulation of the CajalRetzius cell family. We carried out double labeling to substanti- ate the segregation of monolayer and Reln-positive subpial compartment; however, our technique did not allow us to reliably assess colocalization of GAD and Reln, or CR and Reln in the same cell, and further studies are needed to sort out the neurochemical profiles of preplate neurons. Similarly, the question of the origin of these GAD-ir neurons cannot be addressed in our material. They may have a local origin, or they may migrate from ganglionic eminences, as do GABAergic interneurons and some Cajal-Retzius cells in rodents (Anderson et al., 1997; Tamamaki et al., 1997; Lavdas et al., 1999).

Our results suggest that the GAD-ir monolayer neurons remain in a superficial position relative to pioneer plate and cortical plate. They may form a barrier between MZ and $\mathrm{CP}$, and they may play a role at the end of the migratory pathway, when $\mathrm{CP}$ neurons detach from their radial glia guide on reaching the upper border of the CP. Certainly this cell type deserves further characterization.

\section{Pioneer cells}

Stage 21 is characterized by the aggregation of rounded neurons that are CR-ir but GAD- and Reln-negative and thus different from the horizontal monolayer neurons. We name these cells "pioneer cells" because they emit descending axons that course into the intermediate zone. The initial condensation of pioneer neurons has no recognizable radial organization, which sets it apart from the radially organized cortical plate. The superficial pioneer neurons may be homologous to the transient pioneer neurons described in the rat MZ (Meyer et al., 1998), whereas the deep component would correspond to the rodent subplate (Bayer and Altman, 1990; de Carlos and O’Leary, 1992) or human presubplate (Kostovic and Rakic, 1990). Rat pioneer neurons both in $\mathrm{MZ}$ and subplate contribute the first efferent fibers to the internal capsule (de Carlos and O'Leary, 1992; Meyer et al., 1998; Molnár et al., 1998). There are important differences, however, between rat and human pioneer neurons. First, in rat, MZpioneer neurons are born before most Reln-ir Cajal-Retzius cells (Meyer et al., 1998), whereas in man they appear relatively late, almost concurrently with cortical plate neurons. As described above, the first stages of human preplate are dominated by Reln-ir neurons, not by Reln-negative pioneer neurons. We cannot rule out the possibility that we failed to detect early human pioneer neurons; however, in cresyl violet-stained sections, we did not observe any large rounded cell body before stages 20/21. A second difference becomes evident after the insertion of the first cortical plate contingent into the pioneer plate: the proportion of pioneer cells remaining at the upper border of the $\mathrm{CP}$, relative to those that settle in the subplate, is lower in man than in rat. In man, the pioneer plate is thus divided into a minor superficial cell population, and a larger subplate component, by the first migratory cohort of the $\mathrm{CP}$ proper. It is worth pointing out, however, that the development of the human subplate is a protracted process that extends over several months (Kostovic and Rakic, 1990). The subplate, or presubplate described here, may be the earliest representative of a larger neuronal network.

\section{Pioneer plate partition and $\mathrm{CP}$ formation}

During the initial appearance of the CP, Reln-positive cells remain in a strictly subpial location and are thus not physically implicated in preplate partition. It is the insertion of the $\mathrm{CP}$ within the framework of the pioneer neurons that results in the partition of the pioneer plate. Whereas CP neurons are characterized by their radial arrangement, with the appearance of the 
CP the subplate neurons also assume a pyramidal shape and radial orientation. However, the differentiated processes of subplate neurons, usually several basal dendrites and a single apical dendrite, indicate a high degree of maturity, in contrast with the immature morphology and tight compaction of CP neurons. This is in keeping with the concept of the subplate as an early compartment involved in pathfinding of pioneer efferent and afferent fibers (Allendoerfer and Shatz, 1994). The pioneer neurons in the deep MZ become increasingly spaced as development proceeds, which may be caused by dilution or cell death, as in the rat where they disappear before birth (Meyer et al., 1998).

The developmental sequence outlined here implies that complex cellular events take place during early corticogenesis. The ongoing characterization of mouse mutations that perturb early corticogenesis in specific and diverse ways shows that a whole integrated molecular network remains to be sorted out. The reeler-like phenotype is generated by mutations not only of the reeler gene but also of the disabled 1-gene (Howell et al., 1997; Sheldon et al., 1997; Ware et al., 1997; Rice et al., 1998) and in mice that are doubly deficient for the lipoprotein receptors VLDLR and ApoER2 (Trommsdorff et al., 1999), suggesting that these genes form part of a "reelin-signaling pathway" (Bar and Goffinet, 1999; Cooper and Howell, 1999). The cellular counterpart of this molecular pathway is presumably more intricate than the conventional preplate scheme of Cajal-Retzius and subplate neurons. Our study provides evidence that the Reln-expressing neurons in the MZ, usually identified as Cajal-Retzius cells, are not directly involved in preplate partition. Similarly, the role of the monolayer neurons, perhaps the first cellular target in the Reln-signaling pathway, should be examined further in animal models. Presumably, the situation in man is even more complex, and some malformations may result from mutations in genes that control specific events in corticogenesis. The present work should be considered a first attempt to deal with this complexity.

\section{REFERENCES}

Alcántara S, Ruiz M, D’Arcangelo G, Ezan F, De Lecea L, Curran T, Sotelo C, Soriano E (1998) Regional and cellular patterns of reelin mRNA expression in the forebrain of the developing and adult mouse. J Neurosci 18:7779-7799.

Allendoerfer KL, Shatz CJ (1994) The subplate, a transient neocortical structure: its role in the development of connections between thalamus and cortex. Annu Rev Neurosci 17:185-218.

Anderson SA, Eisenstat DD, Shi L, Rubenstein JLR (1997) Migration of interneuron precursors from the basal forebrain to the neocortex: dependence on Dlx-1 and Dlx-2. Science 278:474-476.

Angevine JB, Sidman RL (1961) Autoradiographic study of cell migration during histogenesis of cerebral cortex in the mouse. Nature 192:766-768

Austin CP, Cepko CL (1990) Cellular migration patterns in the developing mouse cerebral cortex. Development 110:713-732.

Bar I, Goffinet AM (1999) Decoding the Reelin signal. Nature 399:645-646.

Bayer SA, Altman J (1990) Development of layer I and the subplate in the rat neocortex. Exp Neurol 107:48-62.

Caviness VS (1982) Neocortical histogenesis in normal and reeler mice: a developmental study based upon $\left[{ }^{3} \mathrm{H}\right]$ thymidine autoradiography. Dev Brain Res. 4:293-302.

Chun JJ, Shatz CJ (1989) The earliest-generated neurons of the cat cerebral cortex: characterization by MAP2 and neurotransmitter immunohistochemistry during fetal life. J Neurosci 9:1648-1667.

Cooper JA, Howell BW (1999) Lipoprotein receptors: Signaling functions in the brain? Cell 97:671-674.

D’Arcangelo G, Miao GG, Chen SC, Soares HD, Morgan JI, Curran T (1995) A protein related to extracellular matrix proteins deleted in the mouse mutant reeler. Nature 374:719-723.

D’Arcangelo G, Nakajima K, Miyata T, Ogawa M, Mikoshiba K, Curran
T (1997) Reelin is a secreted glycoprotein recognized by the CajalRetzius-50 monoclonal antibody. J Neurosci 17:23-31.

de Bergeyck V, Naerhuyzen B, Goffinet AM, Lambert de Rouvroit C (1998) A panel of monoclonal antibodies against reelin, the extracellular matrix protein defective in reeler mutant mice. J Neurosci Methods 82:17-24.

de Carlos JA, O'Leary DDM (1992) Growth and targeting of subplate axons and establishment of major cortical pathways. J Neurosci 12:1194-1211.

des Portes V, Pinard JM, Billuard P, Vinet MC, Koulakoff A, Carrié A, Gelot A, Dupuis E, Motte J, Berwald-Netter Y, Ctala M, Kahn A, Beljord C, Chelly J (1998) A novel CNS gene required for neuronal migration and involved in $\mathrm{X}$-linked subcortical laminar heterotopia and lissencephaly syndrome. Cell 92:51-61.

Evers P, Uylings HBM (1994) Microwave-stimulated antigen retrieval is $\mathrm{pH}$ and temperature dependent. J Histochem Cytochem 42:1555-1563.

Faiella A, Brunelli S, Granata T, D'Incerti L, Cardini R, Lenti C, Battaglia G, Boncinelli E (1997) A number of schizencephaly patients including 2 brothers are heterozygous for germline mutations in the homeobox gene EMX2. Eur J Hum Genet 5:186-190.

Francis F, Koulakoff A, Boucher D, Chafey P, Schaar B, Vinet MC, Friocourt G, McDonnell N, Reiner O, Kahn A, McConnell SK, Berwald-Netter Y, Denoulet P, Chelly J (1999) Doublecortin is a developmentally regulated, microtubule-associated protein expressed in migrating and differentiating neurons. Neuron 23:247-256.

Gleeson JG, Allen KM, Fox JW, Lamperti ED, Berkovic S, Scheffer I, Cooper EC, Dobyns WB, Minnerath SR, Ross ME, Walsh CA (1998) Doublecortin, a brain-specific gene mutated in human X-linked lissencephaly and double cortex syndrome, encodes a putative signaling protein. Cell 9:63-72.

Gleeson JG, Lin PT, Flanagan LA, Walsh CA (1999) Doublecortin is a microtubule-associated protein and is expressed widely by migrating neurons. Neuron 23:257-271.

Goffinet AM (1984) Events governing organization of postmigratory neurons: studies on brain development in normal and reeler mice. Brain Res Rev 7:261-296.

Howell BW, Hawkes R, Soriano P, Cooper JA (1997) Neuronal position in the developing mouse brain is regulated by mouse disabled- 1 . Nature 389:733-737.

Kostovic I, Rakic P (1980) Cytology and time of origin of interstitial neurons in the white matter in infant and adult human and monkey telencephalon. J Neurocytol 9:219-242.

Kostovic I, Rakic P (1990) Developmental history of the transient subplate zone in the visual and somatosensory cortex of the macaque monkey and human brain. J Comp Neurol 297:441-470.

Lambert de Rouvroit C, Goffinet AM (1998) The reeler mouse as a model of brain development. Adv Anat Embryol Cell Biol 150:1-108.

Lavdas AA, Grigoriou M, Pachnis V, Parnavelas JG (1999) The medial ganglionic eminence gives rise to a population of early neurons in the developing cerebral cortex. J Neurosci 19:7881-7888.

Luskin MB, Shatz CJ (1985) Studies of the earliest generated cells of the cat's visual cortex: cogeneration of subplate and marginal zones. J Neurosci 5:1062-1075.

Marín-Padilla M (1971) Early prenatal ontogenesis of the cerebral cortex (neocortex) of the cat (Felis domestica). A Golgi study. I. The primordial neocortical organization. Z Anat Entwicklungsgesch 134:117-145.

Marín-Padilla M (1972) Prenatal ontogenetic history of the principal neurons of the neocortex of the cat (Felis domestica). A Golgi study. II. Developmental differences and their significances. Z Anat Entwicklungsgesch 136:125-142.

Marín-Padilla M (1998) Cajal-Retzius cells and the development of the neocortex. Trends Neurosci 21:64-71.

Meyer G, Goffinet AM (1998) Prenatal development of reelinimmunoreactive neurons in the human neocortex. J Comp Neurol 397:29-40.

Meyer G, Wahle P (1999) The paleocortical ventricle is the origin of reelin-expressing neurons in the marginal zone of the fetal human neocortex. Eur J Neurosci 11:3937-3944.

Meyer G, Gonzalez-Hernandez T (1993) Developmental changes in layer I of the human neocortex during prenatal life: a DiI-tracing and AChE and NADPH-d histochemistry study. J Comp Neurol 338:317-336.

Meyer G, Soria JM, Martínez-Galán JR, Martín-Clemente B, Fairén A (1998) Different origins and developmental histories of transient neu- 
rons in the marginal zone of the fetal and neonatal rat cortex. J Comp Neurol 397:493-518.

Molnár Z, Adams R, Blakemore C (1998) Mechanisms underlying the early establishment of thalamocortical connections in the rat. J Neurosci 18:5723-5745.

O'Rahilly R, Müller F (1994) The embryonic human brain. An atlas of developmental stages. New York: Wiley-Liss.

O'Rourke NA, Dailey ME, Smith SJ, McConnell SK (1992) Diverse migratory pathways in the developing cerebral cortex. Science 258:299-302.

O'Rourke NA, Sullivan DP, Kaznowski CE, Jacobs AA, McConnell SK (1995) Tangential migration of neurons in the developing cerebral cortex. Development 121:2165-2176.

Pearlman AL, Faust PL, Hatten ME, Brunstrom JE (1998) New directions for neuronal migration. Curr Opin Neurobiol 8:45-54.

Raedler E, Raedler A (1978) Autoradiographic study of early ontogenesis in rat neocortex. Anat Embryol 154:267-284.

Rakic P (1972) Mode of cell migration to the superficial layers of fetal monkey neocortex. J Comp Neurol 145:61-84.

Rakic P (1974) Neurons in rhesus monkey visual cortex: systematic relation between time of origin and eventual disposition. Science 183:425-427.

Rice DS, Sheldon M, D'Arcangelo G, Nakajima K, Goldowitz D, Curran T (1998) Disabled-1 acts downstream of Reelin in a signaling pathway that controls laminar organization in the mammalian brain. Development 125:3719-3729.

Rickmann M, Wolff JR (1981) Differentiation of "preplate" neurons in the pallium of the rat. Bibl Anat 19:142-146.
Sheldon M, Rice DS, D'Arcangelo G, Yoneshima H, Nakajima K, Mikoshiba K, Howell B, Cooper JA, Goldowitz, Curran T (1997) Scrambler and yotari disrupt the disabled gene and produce a reeler-like phenotype in mice. Nature 389:730-733.

Sheppard AM, Pearlman AL (1997) Abnormal reorganization of preplate neurons and their associated extracellular matrix: an early manifestation of altered neocortical development in the reeler mutant mouse. J Comp Neurol 378:173-179.

Supèr H, Soriano E, Uylings HBM (1998) The functions of the preplate in development and evolution of the neocortex and hippocampus. Brain Res Rev 27:40-64.

Tamamaki N, Fujimori KE, Takauji R (1997) Origin and route of tangentially migrating neurons in the developing neocortical intermediate zone. J Neurosci 17:8313-8323.

Trommsdorff M, Gotthardt M, Hiesberger T, Shelton J, Stockinger W, Nimpf J, Hammer RE, Richardson JA, Herz J (1999) Reeler/ Disabled-like disruption of neuronal migration in knockout mice lacking the VLDL receptor and ApoE receptor. Cell 97:689-701.

Ware ML, Fox JW, Davis NM, Lambert de Rouvroit C, Russo C, Chua SC, Goffinet AM, Walsh CA (1997) Aberrant splicing of a mouse disabled homolog, mDab1, in the scrambler mouse. Neuron 19:239-249.

Wood JG, Martin S, Price DJ (1992) Evidence that the earliest generated cells of the murine cerebral cortex form a transient population in the subplate and marginal zone. Dev Brain Res 66:137-140.

Zecevic N, Milosevic A (1997) Initial development of $\gamma$-aminobutyric acid immunoreactivity in the human cerebral cortex. J Comp Neurol 380:495-506 